beg to state, that there being 2914 Poor-Law Medical Officers, they have received 343 subscriptions only, since the meeting on the 19th February, and of these, several were from gentlemen who had subscribed once, and in one instance twice, before.

It is hoped, therefore, that those gentlemen who have as yet contributed nuthing, will not consider themselves as excused from assisting, in however small a degree, the fund for the purposes already stated.

I have the honour to remain, Gentlemen, Your obedient servant, THOMAS MARTIN, Treasurer to the Committee

Reigate, April 30, 1849.

\section{INTRAMURAL INTERMENT.}

To the Honourable the Commons of the United Kingdom of Great Britain and Ireland in Parliament assembled.

The Petition of the President and Council of the Gloucestershire Medical and Surgical Association,

\section{Showeth,-}

That your Petitioners are of opinion that the interment of the dead in towns and populous districts is highly injurious to the public health, and that no measure of Sanitary Reform is complete unless this obnoxious system is at once and for ever abolished by legislative enactment.

That your Petitioners desire to express their unfeigned satisfaction that this national grievance was the subject of inquiry by a Committee of your Honourable House in the year one thousand eight hundred and forty-two, who reported, that " after a long and patient investigation, your Committee cannot arrive at any other conclusion than that the nuisance of interments in large towns, and the injury arising to the health of the community from the practice, are fully proved."

That, from the evidence adduced before the Committee, and the many subsequent exposures of the lamentable and terrible consequences resulting, and necessarily arising, from the present system of interment, your Petitioners venture to express their earnest desire, that the burial of the dead in the midst of the living may be prohibited by the closing of all burial places in cities, towns, and populous districts, and by the adoption of such measures as may secure the public from the injurious and debasing practices at present existing.

That your Petitioners curdially support the efforts now making by the National Society for the abolition of burials in towns, and they desire respectfully to add their testimony and influence, as experienced medical practitioners, in aid of a measure at once politic and humane, and worthy of an advanced civilisation.

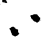

\section{NOTES ON AMERICA : ITS MEDICAL SCHOOLS AND ESTABLISHMENTS.*}

By Edward Humpage, Esq., M.R.C.S., Bristol.

Quarantine Establishment: Cholera: Yellow Fever: Gastro Enteritis.

In the beantiful Bay of New York lies Staten Island, which from its lovely situation is the resort of many of the wealthy citizens, especially in the summer season, at which time the air is so much cooler than in the neighbouring city. The splendid villas of the merchants rise in all imaginable shapes on the fine slopes of the western extremity of the island, and add much to the surpassing beauty of this magnificent bay. Here also is the Government Depôt for invalids, as they arrive on board the various emigrant ships from Europe. It is a most extensive range of build. ings, and is known as the "Quarantine Ground," comprehending a Marine Hospital, for the reception af patients suffering from contagious diseases, a depart. ment for yellow fever, a small-pox hospital, besides several other buildinge for the use of the physicians, health officer, and others. The whole establishment is on a very large scale, and will afford accommodation for 1000 invalids. By the politeness of two of the medical officers, Dr. Whiting and Dr. Cucha, I had the privilege of visiting this excellent establishment on tro or three occasions.

By the laws of the State of New York, all foreign ships entering the bay must cast anchor on the Quarantine Ground, hoist the yellow flag, and be subjected to an examination by the health officer, who, on finding the crew and passengers healthy, gives a certificate that admits them into port. This precaution is highly necessary, from the multitudes of emigrants constantly arriving from Europe, among whom ship-fever so frequently prevails. All cases of diseases are immediately removed into the hospital, so that sometimes they have a sudden accession of patients, amounting to three or four hundred, the great majority being Irish or Germans. On my first visit I saw a large number of the latter just imported from Bremen; they were suffering from fever and dysentery. The treatment adopted is very simple, such as abdominal fomentations, small doses of grey powder, with Dover's powder at night, and chalk mixture or salines, according to circumstances. When there is much cerebral disturbance, the head is shaved, and ice or evaporating lotion is used; depletion is not well borne, and rarely or ever practised. Much importance is attached to ventilation, which is practised to an extent very far beyond that adopted in English hospitals, and the temperature of the wards is usually sixty degrees,-never more than sixty-five degrees, Fahrenheit.

The different apartments being constructed of wood, openings, about two feet by one, are cut in the walls, at intervals of twelve or fourteen feet, just above the floor; these openings being opposite each other, afford a fine current of fresh air; and the same arrangement 
being adopted near the roof, most completely prevents any accumulation of foul air, and thus the fresh air becomes a constant remedy in the treatment of disease, affording an illustration of the good effects of pure air, and of its immense value as a prophylactic agent. Many of the cases admitted, indeed, recover merely by the use of a simple diet, and the change of air from the crowded steerage of the emigrant ship, to these well-ventilated and comfortable apartments.

Cases of yellow fever had been numerous during the autumn, as it appeared among the soldiers returning from the war in Mexico.

I saw the peculiar "vomit" of the disease, many specimens of which were preserved in sealed bottles; it was evidently sanguineous, and corresponded with the usual description of coffee grounds. This fearful malady is treated on general principles, it is regarded as fever of a typhoid type, and a very gentle and careful management succeeded best, the " medicina perturbatrix," being quite out of the question. It is frequently observed, that chronic dysentery is the sequela of yellow fever, and is best combatted by the use of the nitrate of silver, on which more dependance is placed, than on the sulphate of copper.

On my second visit to the Quarantine Establisbment, (December 4th,) I found some consternation excited by the presence of cholera; its introduction took place by the arrival of the packet ship New York, from Havrode.grace. The history given by the Captain was, that after being at sea fourteen days, several of the passengers became sick, had diarrhœa, and in a few days some died; these cases were followed by others, showing more severe, and rapidly fatal, symptoms. Fifteen cases had been received into the hospital, of which seven had proved fatal : eight were under treatment, one of which, a child about eight years old, was very characteristic of the disease as we saw it in England in 1832,- the sunken eye, collapsed features, cold tongue, contraction of the abdominal muscles, and rice-coloured evacuations. The child was seized about fourteen hours before my visit; she died in four hours afterwards. Another case was that of a woman far advanced in pregnancy; she was seized with the usual symptoms, and died in twelve hours. The treatment adopted was the use of the hot-air apparatus, and frictions of the surface with tinctura capsici ; calomel was administered internally, and $I$. believe also opium, but here, as everywhere else, the awful rapidity of progress entirely connteracts the influence of ordinary remedies. In the cases which recovered the symptoms were milder, and thus afforded time for the successful exhibition of remedies.

The origin of cholera on board this emigrant ship would lead us to believe in the spontaneous generation of the disease, under peculiar circumstances. The passengers and crew left Havre all well; there was no cholera in the town. Thenumber on board was upwards of 300 , and they were badly provisioned, so that com. plaints had arisen among them about the food and water before any symptoms of disorder appeared. No systematic ventilation was practised, nor had the ship any surgeon, so that everything concurred to favour the appearance of disease.
It was remarked by the Captain, that at the time he first heard of any sickness among the people, (being off the coast of Nova Scotia,) the thermometer fell eighteen degrees within a few hours; how far this was a coincidence, or had any relation to the sudden appearance of diarrbœa, of course is matter of conjecture. The emigrants thus affected had not been in the hospital many days before several convalescents were attacked, and some died, with ull the symptoms of cholera, so that the impression on the minds of the medical attendants was, that under certain circumstances the disease was contagious; the patients in the convalescent ward were separated entirely from the new patients, and I believe no farther propagation of the disease among them took place. It should be stated that these convalescents were all parties who were just recovering from gastric fever, and therefore would be peculiarly liable to such an attack.

My own impression is, that the poison of cholera may be propagated from one person to another under peculiar circumstances, but that, with ordinary precau. tion as to cleanliness and ventilation, we may generally prevent such a thing from occurring.

The appearance of the disease on board this emigrant ship shows how important is the appointment of a surgeon, as there is every reason to believe that in this instance the malignity of the disease was entirely owing to an accumulation of filth in the steerage of the vessel, and to the neglect of the early symptoms of sickness and diarrhce.

Since I left New York the statement of the appearance of cholera in several of the transatlantic cities is confirmed, and I should fear, with the approach of warm weather, we may expect to hear of a serious return of the disease in a climate where gastric irritation is so common, and diseases of the mucous membranes always rife.

(To be continued.)

\section{Gefneral Retrospect.}

\section{PHYSIOLOGY.}

ON THE STRUCTURe OF THE PAPILLE OF THB TONGUE.

Mr. Hassal states that a minute and careful examination of the papillæ of the tongue has convinced him that the term conical, as applied to certain papillw of that organ, is a misnomer, and that these are excavated and cupped in form.

Corresponding with this general shape of the papille, and determined by it, is the arrangement of the secondary papillæ, of a number of which each compound papilla is made up in a circle, the boundary of which corresponds with the raised margin of each cup.

The vessels and nerves supplying these papilla of course follow a similar circular distribution. .

In the recent state, and while the epithelium still remains attached to the subjacent structures, it is - not easy to make out the true form of these cupped papillæ, in 'consequence of the number of filiform processes which are attached to them, obscuring it; 